\title{
Fortuna de un verso de Sannazaro: para una metafísica del olvido en la poesía española del Siglo de Oro
}

\author{
Fortune of Sannazaro's verse: for a metaphysics \\ of the oblivion in the Spanish poetry of the Golden Century
}

Bienvenido Morros Mestres

Universidad Autónoma de Barcelona

Para Daniel Fernández y José María Micó

RESUMEN: El presente trabajo estudia el tema del amor más allá del olvido entre los poetas del siglo de oro. Todos ellos lo trataron por influencia de un idilio atribuido a Teócrito y que en el Renacimiento fue muy conocido porque se tradujo también al latín: los primeros en plantearlo fueron Joan Roís de Corella y Jacopo Sannazaro ya en la segunda mitad del siglo XV. Por influencia del italiano los autores posteriores ya lo desarrollaron ampliamente.

Palabras clave: literatura clásica, mitología, amor y muerte, poetas italianos y españoles del Renacimiento y Barroco.

ABSTRACT: This work explores the theme of love beyond the forgetfulness among the poets of the golden age. All they tried under the influence of a love affair attributed to Theocritus and which in the Renaissance was well known because it was translated also into latin: the first to raise it were Joan Roís de Corella and Jacopo Sannazaro already in the second half of the 15th century. By the Italian influence later authors already developed it widely.

Keywords: classic literature, mythology, love and death, Italian and Spanish poets of the Renaissance and Baroque. 
El poeta inglés John Carey, afincado en Italia, donde se dio a conocer como Giovanni Caregli, había escrito en la segunda mitad del siglo XVII el verso “Avranno pace ceneri de' miei" para proclamar que seguiría amando a Irene (en griego significa 'paz') y también pronunciando su bello nombre en los oscuros reinos del espanto ${ }^{1}$. El poeta inglés, en cambio, no llegó a determinar si ese gran amor por Irene era tan fuerte que incluso podía sobrevivir a las terribles aguas del río Leteo. Los poetas italianos, a quienes John Carey debió de haber leído durante su estancia en Italia, sí contemplaron esa posibilidad porque a partir de Sannazaro habían conocido un magnífico idilio atribuido a Teócrito en que su protagonista anunciaba a su desdeñoso amante la decisión de suicidarse para beberse el largo olvido y así apagar su deseo (pero también le hacía saber que su deseo era mucho más largo que el olvido y que preveía seguir encendido incluso después de apurar hasta la última de sus sedantes y tranquilizadoras aguas). Es una posibilidad que incluso llegaron a plantear los poetas de las llamadas generaciones del 1898 y del 1927 porque sin duda estuvieron familiarizados con esa larga tradición que arranca en el Renacimiento y se perpetúa en el Barroco por la gran difusión de un verso del poeta napolitano. En las páginas que siguen nos limitaremos a estudiar los poetas de nuestro siglo de oro que postularon toda una metafísica del olvido.

\section{SANNAZARO Y SUS FUENTES}

\section{Fuentes Clásicas}

Sannazaro decidió rendir homenaje al final de su Arcadia (Nápoles, 1504) a su maestro y amigo Giovanni Pontano al hacerlo aparecer en su obra junto a otros dos pastores (el Cariteo y Pietro Summonte) para lamentar la muerte de su esposa Adriana Sassone. Tras oír a sus dos compañeros, Pontano (que adopta el nombre pastoril de Meliseo) interviene para recordar que conserva en un cestillo algunos cabellos de su esposa sobre los que — cuando los ha sacado de donde los guarda - derrama sus abundantes lágrimas. Acaba pidiendo a su difunta esposa que piense en su vida terrenal junto a él si es que el amor sobrevive al cruzar el río del olvido:

Deh pensa, prego, al bel viver pretèrito,

Se nel passar di Lete amor non perdéis (Sannazaro, 1990: 237).

Los editores y estudiosos, hasta donde alcanzo, no han señalado ningún modelo para esos versos finales de la Arcadia. Pero es posible que Sannazaro

\footnotetext{
${ }^{1}$ Para nuestro desconocido poeta, del que se han conservado muy pocos versos, véase Fox, Morcillo y Mondolfo (1983).
} 
se haya basado en otros de una famosa elegía de Propercio que Francisco de Quevedo, entre otros muchos, había leído con especial atención. Es una elegía en que el poeta latino se imagina amando a Cintia también en el país de la muerte, al igual que el tesalio Protesilao, a quien representa - tras caer en la guerra de Troya - como un fantasma que regresa unos instantes a la vida para gozar sólo unas horas de los placeres de su fiel esposa Laodamia. Propercio asegura que en ese nuevo país su gran amor hará frente a todos los obstáculos que le salgan al paso para superarlos con la garantía del éxito que le da el verdadero amor:

Illic, quidquid ero, semper tua dicar imago:

Traicit et fati litora magnus amor (I, 19, 11-12) (Propercio, 1963: 19).

(Allí, cualquier cosa que yo sea, siempre seré llamado tu sombra: y mi gran amor pasará al otro lado de las riberas de la muerte)

El amante de Cintia se representa a sí mismo como sombra que atraviesa un río porque menciona las "fati litora", en cuyas aguas habrá de exponerse al mayor peligro para un amor que quiere que dure más que la vida. Pero en esa representación no da ningún dato sobre el tipo de prueba a la que en ese río habrá de someterse su gran amor. Podría estar aludiendo simplemente al río Aqueronte y al viaje a través de sus aguas (siempre a bordo de la barca de Carón) hacia la orilla de la muerte. Pero tampoco cabe descartar una referencia al río Leteo y a los efectos amnésicos que producen sus aguas en las almas que se atreven a recorrerlas no siempre en una barca. Si su amor llega a atravesar el primer río habrá vencido a la muerte, y si logra cruzar el segundo habrá superado el olvido. Si tuviera que decantarme por el tipo de obstáculo (muerte u olvido) que menciona el poeta latino en esos versos lo haría por la muerte antes que por el olvido.

En los cuatro inmediatamente anteriores, Propercio narra el viaje de la sombra del tesalio Protesilao desde el lugar que le ha sido asignado en el Hades por su tipo de muerte a la casa que en vida había compartido con su esposa Laodamia. Ese lugar sólo puede situarse después de la muerte (el río Aqueronte) pero nunca después del olvido (el río Leteo), porque la sombra del héroe tesalio no ha podido olvidar en los "cieci... locis" en los que ha sido confinada los placeres que había alcanzado con su adorable esposa cuando aún era mortal. Las sombras que beben las aguas del Leteo olvidan por completo la vida anterior porque se preparan para un posible retorno a otra distinta en un nuevo cuerpo. Esa es la gran diferencia entre la muerte y el olvido: la muerte no logra extinguir el deseo y el amor mientras que el olvido sí lo consigue.

En una elegía del último libro, Propercio ve en sueños la sombra (no el alma) de su amada Cintia, que le describe desde el más allá el mundo oscuro 
de la muerte que ya empieza a serle familiar: el río Aqueronte cuyas aguas circulan en direcciones opuestas llevando hacia un lado tanto las sombras de la adúltera Clitemnestra como la de Pasifae y hacia el otro tanto la de Andrómeda como la Hipermestra, las dos ejemplos de esposas fieles. Sin precisar ningún lugar en concreto pero en probable alusión a los "lugentes campi" virgilianos, Cintia menciona las lágrimas derramadas en el mundo de los muertos para restañar los amores de los vivos:

Sic mortis lacrimis vitae sanamus amores (IV, 7, 69) (Propercio, 1963: 222).

(Así sanamos los amores de la vida con las lágrimas de la muerte)

La dorada Cintia (por su pelo rubio) termina su intervención refiriéndose a las puertas piadosas de los Campos Elíseos que permiten a las sombras el regreso a la tierra. Se despide anunciándole a su poeta que en la inmortalidad lo tendrá para ella sola sin compartirlo con ninguna otra. Parece imaginarse un lugar donde poder prolongar su amor más largo que la muerte pero más corto que el olvido: un lugar en que con las lágrimas de los dos restañar las infidelidades cometidas en vida. No parece que ese lugar pueda estar muy lejos de los "lugentes campi".

Propercio para ese paisaje del Hades ha debido tener en cuenta el que Virgilio había trazado con absoluta precisión en el libro VI de su Eneida. En esos versos de su poema narra el descenso de Eneas acompañado por la Sibila al mundo de los muertos en los que describe primero el río Aqueronte junto a la laguna Estigia y después dos lugares que presenta alejados entre sí pero con la misma obscuridad y tristeza: "tristis sine sole domos, loca turbida" ("lugares confusos, moradas tristes sin sol"; Virgilio, 1959: 183). En el primero de esos dos lugares, que llama "lugentes campi", sitúa las sombras de varias mujeres (no son todas) que están en ellos por poner fin a sus vidas (Evadne, Laodamia y Dido). Dice que las sombras que permanecen en esos campos han sufrido en vida por un duro amor y que aún tras la muerte lo siguen conservando. En el segundo de los campos, que denomina "arva... ultima", por referencia a los anteriores ("Proxima... loca"), ubica las sombras de los que han sido grandes guerreros y han perdido la vida en el campo de batalla. Tras esos dos campos (el de los amantes y el de los guerreros), señala la bifurcación del camino en dos: uno que a la derecha conduce a los Campos Elíseos (el Paraíso de los cristianos) y otro que a la izquierda lleva al Tártaro (propiamente el Infierno). En un valle apartado de los Campos Elíseos, coloca un bosque con el río Leteo, a cuyas aguas atribuye el poder de la paz y el largo olvido. De esas aguas beben las sombras que pretenden iniciar una vida nueva (borrada de la memoria la anterior) en un cuerpo también distinto. 
Tras repasar brevemente el libro VI de la Enedia, queda claro que los "caecis... loci" en los que Propercio sitúa a Protesilao son los "tristis sine sole domos, loca turbida" en los que Virgilio imagina tanto a amantes y guerreros, unos lugares más cercanos y otros más alejados ("Proxima... loca.... arva... ultima"). El poeta elegiaco debe pensar que el héroe tesalio se halla, por haber caído en la guerra de Troya, en los más alejados pero no parece distinguir a sus habitantes de los más cercanos cuando lo presenta a él sin haber podido olvidar el tipo de amor que había practicado en vida.

Sannazaro, sin embargo, ha entendido "fati litora" no como las orillas del Aqueronte (o de la laguna Estigia) sino como las del Leteo. También podía haber identificado unas con otras, como hicieron otros muchos autores en los siglos posteriores, que no suelen distinguir entre la muerte y el olvido. Es bastante habitual por ejemplo describir al barquero Carón recorriendo las aguas del Leteo cuando las que propiamente recorre son las del Aqueronte o la laguna Estigia.

Sannazaro habría podido leer también uno de los idilios atribuidos a Teócrito, aunque no en la edición de Aldo Manucio de Venecia en 1495. Es un idilio, el XXIII, que constituye la posible fuente del mito de Anajárete e Ifis narrado por Ovidio en las Metamorfosis, XIV. El pseudo-Teócrito narra la historia desgraciada de un hombre adulto que decide suicidarse en la puerta de la casa en la que vive el efebo del que se ha enamorado y que le castiga con su más absoluta indiferencia. Antes de colgarse y poner fin a su vida, el hombre adulto afirma que el amor que siente por el efebo no podrá apagarlo ni bebiendo las aguas del olvido:
$A \lambda \lambda \alpha \beta \alpha \delta i \zeta \omega$

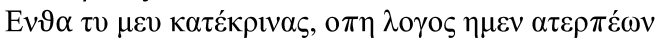

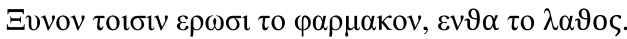

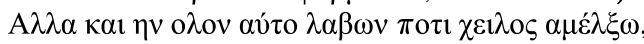

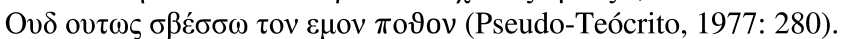

(Pero me encamino al lugar al que tú me has condenado, adonde dicen está para los enamorados el remedio común de sus pesares, al lugar en el que está el olvido; pero aunque lo lleve yo a mis labios y lo beba entero, ni aun así apagaré mi deseo)

Está claro que para el autor de estos versos el amor (o el deseo) no sólo sobrevive a la muerte sino también al olvido. Ovidio, que para sus Metamorfosis (XIV) había adoptado este idilio para confeccionar la fábula de Anájarete, reinterpreta los versos acabados de citar en clave virgiliana al atribuir a Ifis después de muerto el mismo sentimiento de angustia que las sombras en los "lugentes campi": 
Non tamen ante tui curam excessisse memento

Quam vitam (vv. 724-725) (Ovidio, 1983: 157).

(Pero recuerda que la preocupación amorosa por ti no la podré dejar antes que la vida)

En otras obras (posteriores todas), Ovidio vuelve a recrear este motivo pero en una versión más cercana al idilio en cuestión. En sus epístolas escritas desde el destierro, Ovidio recuerda con frecuencia y desde la distancia a los amigos que ha dejado en su querida y añorada Roma; en una incluida entre las enviadas ex Ponto (II, 4), se dirige a uno de esos amigos, posiblemente Curcio Ático, para asegurarle que no se cree que se haya olvidado de las cosas y el afecto que habían compartido en el pasado:

Non ego, si biberes securae pocula Lethes,

Excidere haec credam pectore posse tuo (vv. 23-24) (Ovidio, 1975: 340).

(Ni yo creeré que, cuando bebas las aguas apacibles del Leteo, puedas arrancar estas cosas de tu pecho)

El poeta latino no hace más que, también siguiendo a Virgilio, suponer en las aguas del olvido los efectos calmantes o tranquilizadores que la muerte no consigue provocar entre las sombras destinadas a ocupar los "lugentes campi". En otra carta del mismo libro (IV, 1), Ovidio intenta disculparse ante Pompeyo Magno por no haberlo mencionado en sus versos, certificándole que ni el río Leteo podrá hacer que se olvide de él:

Da mihi, siquid ea est, hebetantem pectora Lethen, Oblitus potero non tamen esse tui (vv. 17-18) (Ovidio, 1975: 424).

(Entrégame al Leteo, si es que existe, que embota los corazones; no podré, sin embargo, olvidarme de ti)

Ovidio podía haber influido en Sannazaro en la formulación del tópico: al igual que su sucesor, lo cuestiona al introducir en una de sus partes una oración condicional ("Si existe el río que insensibiliza a los corazones...").

El poeta napolitano tendría más fácil la lectura de algunos de los epigramas incluidos en la Antología griega (especialmente VII, 23 y 30) porque los habría podido manejar en la edición publicada por Juan Lascaris en 1494 en Florencia ${ }^{2}$. Podía haberse fijado especialmente en dos de los muchos que el poeta Antípatro de Sidonia había dedicado a los epitafios de Anacreonte. En el primero se refiere a las cenizas del difunto, a las que supone experimentando el mismo placer que había experimentado su dueño en vida:

\footnotetext{
${ }^{2}$ Para las ediciones de esta antología, véase López Pozal (2005).
} 


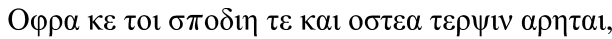

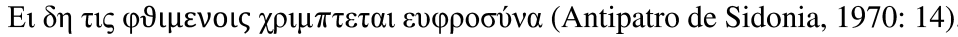

(Que tus cenizas y tus huesos mantengan el placer si es que todavía algún gusto toca a los difuntos)

En el segundo, utiliza la tópica metáfora del amor como un fuego que no sólo no se apaga en las frías regiones de la muerte sino que además enciende las aguas de su río principal:

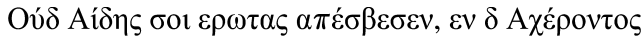

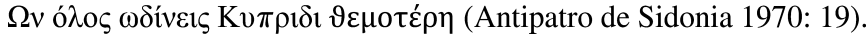

(Ni siquiera el Hades ha disuelto tu amor, y en el Aqueronte sufres el ardor febril de la diosa Afrodita)

Parece evidente que Sannazaro había leído a Virgilio, a Propercio y a Ovidio, y es bastante probable que también hubiera conocido los epigramas que hemos citado de la Antología griega, pero más difícil resulta que hubiera tenido acceso al idilio que algunos manuscritos atribuyen a Teócrito. Es un idilio el citado arriba que no me consta que apareciera publicado junto a los otros en su primera edición, la de 1494; pero que ya traduce al latín el humanista Vicente Mariner en 1620 (v. Castro de Castro, en línea).

\section{FUENTES ITALIANAS}

Nuestro poeta napolitano sin duda también llegó a tener en cuenta diversos pasajes en que Boccaccio desarrolla el tema del amor constante más allá de la muerte pero sin dejar en ningún ejemplo claro si lo considera inmune o no al olvido. Boccaccio sin duda también había leído las elegías de Propercio (podía haberlo hecho en el manuscrito que poseía su amigo Petrarca) y parece, como veremos a continuación, interpretarlas con más exactitud que Sannazaro.

En su obra más famosa, el Decameron, Boccaccio formula el tópico con la misma construcción en condicional que el autor de la Arcadia. La viuda Gismonda, poco antes de poner fin a su vida, se reafirma en su amor por Guiscardo, cuyo corazón servido en una copa de oro le había mandado su padre:

E quanto io viverò, che sarà poco, l'amerò, e se appresso la morte s'ama, non mi rimarrò d'amarlo (IV, 1) (Boccaccio, 1990: 478).

Tras morir Pasquino y Simona envenenados en el huerto en que se habían amado por primera y última vez, la voz del narrador se imagina las almas de los dos amantes muy felices en el mundo de los muertos: 
O felicissime, se nell'altra vita s'ama e voi v'amate come di qua faceste (IV, 7) (Boccaccio, 1990: 552).

En la Fiammetta, la protagonista, al recordar las penas de Píramo y Tisbe, al final de la obra, también interpela las almas de los adolescentes babilónicos para plantear la misma duda sobre su felicidad en el lugar en el que presuntamente pasarán su inmortalidad:

Oh, felici anime le loro, se cosí nell'altro mondo s'ama come in questo! Niuna pena di quello si potrà adeguare al dilecto della loro eterna compagnia (VIII) (Boccaccio, 1987: 222).

$\mathrm{Ni}$ en estos ni en otros ejemplos del motivo, Boccaccio menciona el río Leteo, porque sitúa también en los "lugentes campi" el lugar en el que supone a los amantes después de su muerte. Es fácil hacer esa deducción porque el amigo de Petrarca se imagina a Píramo y Tisbe en un infierno en que el deseo que puedan sentir por estar juntos es superior a los castigos que puedan sufrir por haberse quitado la vida. Al presentarlos como pareja en un lugar en que el deseo no se extingue ni con la muerte recuerda a Francesca y Paolo compartiendo el placer que les ha sobrevivido para durar siempre en el segundo círculo del infierno de Dante:

Amor, ch'a nullo amato amar perdona,

Mi prese del costui piacer sì forte

Che, come vedi, ancor non m'abbandona (V, 103-105) (Dante, 1976: 122).

El amante de Beatriz ha situado a esos amantes contemporáneos en los "lugentes campi", precisamente porque les ha atribuido en la muerte la misma lujuria que habían sentido en vida. Si lo hace, desafiando las leyes de la naturaleza, es porque conoce las "curae" que Virgilio supone en las sombras que tras cruzar el Aqueronte han llegado a esos campos del llanto. Dante emplea el mismo tipo de verbo, perteneciente al mismo campo semántico, que el poeta latino: "Amor [...] del costui piacer... non m'abbandona", "curae... non relinquunt"3. Si decide variar el sujeto de la oración es porque quizá conoce la historia de Protesilao y Laodamia tal como la narra, según acabamos de ver, Propercio en una de sus elegías:

Non potuit caecis immemor esse locis,

Sed cupidus falsis attingere gaudia palmis (I, 19, 8-9) (Propercio, 1983: 39).

(No pude olvidar en los lugares oscuros, sino estaba deseoso de alcanzar los placeres con las manos engañosas)

\footnotetext{
${ }^{3}$ El primer comentarista en darse cuenta de esta deuda más que evidente fue Bernardio Daniello, (Venecia, 1568): "Che, il quale piacer, ancor non m'abbandona, percioche ancora lo amava di là; onde è scritto da Virg. Nel sesto dell'Eneide: 'curae non ipsa in morte relinquunt"; Niccolò Tommaseo (1837) volvió a señalarla: "Abbandona: Aen., VI: "curae non ipsa in morte relinquunt”.
} 
Los comentaristas de Dante tienden a interpretar esos versos de la Divina commedia como un ejemplo del tema del amor (o en sus otras formas, como el deseo o el placer) que perdura más allá de la muerte. De alguna manera lo formulan en unos términos que son los usados por los poetas del Renacimiento y Barroco tanto italiano y español para su tratamiento mayoritario en sus poemas: Bembo, Tansillo, Cetina, Marino, Quevedo, etc. Boccaccio, en cambio, si bien lo desarrolla, como hemos visto, en su obra de creación, lo contradice en su comentario de los versos del infierno dantesco:

Secondo la catolica verità questo [la pervivencia del placer más allá de la muerte] non si dee creyere, per ciò che la divina giustizia non permette che in alcuna guisa alcun dannato abbia o possa avere cosa che al suo desiderio si conformi o gli porga consolazione o piacer alcuno (Pujol, 2013).

Antes de abordar el estudio de todos estos autores, creo necesario citar unos versos de un poeta valenciano, Joan Roís de Corella, que había leído especialmente las obras de Boccaccio, como ya han demostrado sus editores y estudiosos (v. Martos, 2005; Pujol, 2013). En su poema "Cor crudel", recreación sin duda de la fábula de Ifis y Anaxarete, desarrolla un motivo que antes que él ya habían tratado otros dos poetas también valencianos, Gilabert de Pròixita y Jordi de sant Jordi: el de la imagen de la amada que sigue grabada en el alma, corazón o cerebro del amante incluso después de su muerte. Corella reformula el motivo mencionando no sólo la muerte sino también el río Leteo cuyas aguas no conseguir borrar esas imágenes:

Puix que dins mi tinc en bella forma,

Treta del viu en perfeta figura,

Ab les colors sobre 1 fresch, he l'amprenta,

Que ni la mort, ni·l temps, ni l'altre segle

Raure no es pot, ni del riu Letes l'aygua (12-16) (Roís de Corella, 1983: 54).

En años cercanos a los de Sannazaro, Corella, que muere en 1474 y compone la Història de Leàndre i Hero hacia 1460, responde afirmativamente a la pregunta planteada por el autor de la Arcadia: el amor, pues, sobrevive al olvido. Al final de la Història, Hero, al ver aparecer la sombra de Leandro, le anuncia que pronto se reunirá con él y que las almas de los dos seguirán también unidas en los reinos de Plutón:

E no penses, ànima mia de Leànder, llarg espai io et detenga; comporta que al teu cos meu io done sepultura, $\mathrm{i}$ aprés, ensems ab la mia, davallaràs als regnes de Plutò, perquè un carçre, una pena, unes cadenes, après de la mort lliguen aquelles dos ànimes, les quals una amor havia lligat en vida; e així, les cossos morts, abraçats, estaran en un sepulcre, e nosaltres, en dolor vivim, junts en una pena (Roís de Corella, 2001: 179). 
Para esta escena en el Hades, Corella se ha inspirado en el libro VI de la Eneida y el canto V del Inferno de Dante, pero también ha tenido muy presentes los pasajes de las obras de Boccaccio citados arriba. Debe suponer a la pareja de amantes en los "lugentes campi" experimentando los mismos sentimientos que en vida, pero en esos campos los presenta unidos por un amor conyugal, como sugiere al emplear la expresión "les quals una amor havia lligat [aquelles dos ànimes]" (v. Pujol, 2013). En este sentido se aparta de Dante para seguir más de cerca a Virgilio, quien en esos lugares del Hades sitúa a Dido en compañía de su marido Siqueo, con quien comparte la reina de Cartago el amor conyugal de otro tiempo. Precisamente esos versos de la Eneida son los que aduce Boccaccio en el comentario del canto V del Inferno en que niega la posibilidad de un amor o placer ultraterrenal apelando a la fe católica.

En este pasaje de su prosa mitológica, Corella no ha llevado el amor de sus personajes tan lejos como lo había llevado en su poema "Cor crudel", porque lo ha ubicado después de la muerte pero antes del olvido. Es curioso también comprobar cómo concede al amor de Leandro y Hero un tratamiento conyugal intentando desmarcarse de los famosos versos de las Geórgicas de Virgilio, quien lo había medido por el mismo rasero que el instinto sexual de los animales ${ }^{4}$. De manera independiente, ha dado a esa fábula un sentido muy similar al que le había dado Museo en su epilio griego, editado a partir de 1495.

Es curioso que Bernardo Tasso, sin apenas posibilidad de haber leído la prosa mitológica de Corella, prevea en su "Favola di Leandro e d'Ero" el mismo destino para las almas de los dos amantes, con la sola diferencia de llegar a situarlas también en los Campos Elíseos:

Donate i corpi morti a sepultura,

Acciò possin varcar insieme aggiunti

Le nere e torbid'acque di Cocito,

E gira i lieti e fortunati campi,

O pur nel boco degli ombrosi mirti (vv. 671-675) (Tasso, 1995: 411).

Tasso menciona el río Cocito, al que da el mismo valor que el Aqueronte virgiliano, como río que atraviesan las almas de Leandro y Hero para llegar a los lugares que se le asignen después de la muerte. Si las imagina en la selva de los mirtos es porque las supone aún conservando el amor que se habían prodigado en vida; si, en cambio, las sitúa en los Campos Elíseos es porque lo han olvidado tras beber las aguas del Leteo. Por eso Boscán opta por el segundo lugar:

${ }^{4}$ Véase Morros (2013) y también Sebastián Perdices y Morros (2013). 
Y así se fueron juntas las dos almas

A los campos Elíseos para siempre (Boscán, 1992: 324).

Tasso prevé también ese destino para su alma enamorada en un soneto en que recuerda sin duda el famoso verso de Sannazaro (se ha limitado a cambiar la referencia al Leteo por la más general a la Muerte, quizá influido por los epigramas de Antipatro de Sidonia o el de Marullo):

Dal premier ci ch'io vidi i lumi vostri

Divenni vostro, e sarò sin ch'io viva,

Né per mostrarvi disdegnosa e schiva

Cangiar potrete un solo de' pensier nostri;

Testimonio ne fan gli sparsi inchiostri,

Che vi terran per molti tempi viva,

E se Morte d'amor l'alma no priva,

V'amarò ancora ne' superni chiostri (CXIV, 1-8) (Tasso, 1995: 96).

Pero muchos siglos antes que Corella y Tasso (y unos pocos antes del propio Museo) Ausonio había situado en su poema Cupidus cruciatas a Hero en los "lugentes campi" llevando encendida la antorcha con la que había guiado todas las noches a su amante y que simbolizaba su deseo amoroso (la luz está humosa por la oscuridad del lugar en que la muchacha se halla):

Fert fumida testae

Lumina sestiaca praeceps de turre puella (Ausonio, 1971: 598).

(La muchacha lleva la luz ennegrecida de la lámpara precipitándose desde la torre de Sestos)

No muchos años después que Corella un poeta griego afincado en Italia, Michael Marullo, compuso un epigrama a Marzia Bocontia no sólo para establecer una etimología con su nombre sino también para proclamarle un amor al menos más allá de la muerte. Es probable que Francisco Quevedo lo conociera (hay una edición en París de 1561) porque parece inspirarse en varios de sus versos para los finales de su famoso soneto "Cerrar podrá mis ojos la postrera sombra":

Cur tibi Mars tribuit speciosum, Martia, nomen?

An contra quod me tam fera bella facis?

Bella facis faciasque licet, tibi dedita servit

Mens tamen et duros serviet ad cineres.

Quod siquis misero post funera sensus amori est,

Tunc quoque amet vultus ossea forma tuos (Marullus, 2012: 29).

(¿Por qué el ilustre Marte te dio, Marcia, el nombre? ¿Acaso para que hicieras fiera guerra contra mí? Aunque me haces y hagas guerra, sin embargo mi 
alma consagrada a ti te sirve y servirá en las insensibles cenizas. Pues si alguno después de la triste pira funeraria tiene el sentimiento de amor, que entonces también un esqueleto ame tu rostro')

El poeta madrileño pudo tener en cuenta el "sensus amori" "post funera" para las "venas" que acaban siendo "ceniza" con "sentido" y también para las "medulas" que acaban siendo "polvo enamorado": el "sensus amori" es el que experimentan las cenizas del cadáver que ha sido incinerado en la pira funeraria.

\section{LOS IMITADORES DE LOS VERSOS DE SANNAZARO}

Sólo dos años después de la Arcadia, un poeta barcelonés afincado en Nápoles, Benedetto Gareth, apodado el Cariteo, al que Sannazaro, como acabamos de ver, hace aparecer en su obra como el pastor Barcinio, dio a la imprenta su Libro de sonetti et canzone intitulato Endimione a la Luna (1506). Entre los sonetos incluyó uno en que con cierta sorpresa afirma que su sombra no recorrerá las aguas del olvido porque no se la imagina descansando en los lugares más tranquilos y plácidos del Hades:

Se'l parlar perturbato et pien di horrore,

Diverso da l'humano et lieto volto,

Ha possuto privare un core stolto

D'ogni speranza et d'ogni cieco errore;

scemar non può quell'abundante ardore

che vive et cresce sempre dentro occolto;

ma temo ch'io sarò tolto sepulto:

¡Si m'afflige il mortale impio dolore!

Ma s'alcuna ombra in ciel o negli abissi

Riman di poi l'acerba morte mia,

Non girà mai tra l'anime quiete,

Anzi chiamando il nome in ogni via

Di lei, per cui, morendo, al mondo vissi,

Non passarà la negre onde di Lete (Cariteo, 1892: 27).

El Cariteo tiene muy presente el paisaje del mundo de los muertos que Virgilio describe en la Eneida cuando narra el descenso del héroe troyano a sus dominios para encontrarse con su padre. El poeta latino se refiere primero al río Aqueronte y a la laguna Estigia (parece confundirlos) con el barquero Carón que recorre sus aguas; no muy lejos de allí menciona los campos de los que lloran y la selva de los mirtos en que sitúa a las almas de quienes aún en la muerte siguen sufriendo por amor como cuando estaban vivos; por último, tras colocar en unos campos más distantes las almas de los guerreros, alude a 
una bifurcación con un camino a la derecha que lleva a los Campos Elíseos y con otro a la izquierda que conduce al Tártaro. En los Campos Elíseos ubica las almas de los grandes guerreros, de los que han sido castos o de los que han practicado el bien en vida; y en un bosque aparte, el río Leteo, en cuyas aguas beben las almas de quienes desean olvidarlo todo para en miles de años volver a la vida con un nuevo cuerpo. En el Tártaro pone las almas de los malvados que padecen grandes torturas (Sísifo, Ixión, Tántalo, etc).

En ese paisaje tan preciso se entiende la elección que hace el Cariteo. El poeta barcelonés no quiere con su sombra cruzar las aguas del río Leteo porque pretende conservar el amor que tuvo en vida (y sabe que en esas aguas obtendría una tranquilidad y un olvido que no desea para sí ni para su sufrimiento). Por eso prefiere buscar otro destino en el más allá para su sombra: el Tártaro y los campos de los que lloran en la selva de los mirtos. En el soneto descarta los Campos Elíseos y el bosque del río Leteo. Es en la canción que sigue al soneto citado donde precisa el lugar que reserva para su alma:

Canzone, io non fui mai

Nei campi Elisi et fortunate valli,

Ov'altro sol si vede et altra luna,

Né mai l'aëre imbruna,

Né vivo ascoso in quei secreti calli

Coverti d'amorosi, ciprii mirti;

Ma son più giù tra più dolenti spirti (Cariteo, 1892: 30).

Cariteo ha elegido el Tártaro como el lugar en el que desea que vaya su sombra porque en él experimentará mayores torturas y dolores que en vida. $\mathrm{Si}$ ha descartado los campos del llanto es porque en sus sendas secretas sabe que padecerá las mismas preocupaciones que antes de morir. Se plantea la posibilidad de sobrevivir a la muerte en el Tártaro o en los Campos Elíseos, pero descarta, a diferencia de Sannazaro, la de conservar el amor en la travesía por el río Leteo. Sitúa su amor entre la muerte (la laguna Estigia) y el olvido (el río Leteo).

El verso del autor de la Arcadia aparece adaptado muy literalmente en una canción pastoril y una elegía fúnebre atribuidas al poeta Francisco de Figueroa. La elegía, que aparece entre los poemas añadidos de la segunda edición de sus obras (Lisboa, 1626), está escrita con ocasión de la muerte del primogénito de Felipe II, Carlos de Austria, ocurrida en el año 1568:

Si el amor, al pasar del río Leteo,

Serenísimo Carlos, no se olvida;

Si allá se perficiona un buen deseo,

Vuelve los ojos de do Dios se anida

A España [...] (Figueroa 1988: 320). 
El autor de estos versos, casi con toda seguridad de Francisco de Figueroa, comienza la elegía adaptando tan al pie de la letra el verso de Sannazaro, que incluye la palabra "amor" en un contexto en el que no parece demasiado adecuada. En los primeros tercetos (vv. 1-9), se dirige al difunto para pedirle que, de experimentar sensaciones en el lugar en el que se halla, se conmueva de la España que lo llora y la consuele en su tristeza. En los otros tercetos (vv. 1037 , pone en boca de Carlos las palabras con las que intenta aliviar el dolor de su amada patria informándole que goza de los bienes del paraíso acompañado de su madre y abuelo Carlos I.

La canción, que está atribuida en varios manuscritos a Francisco de Figueroa, aunque no parece suya, recrea el tópico horaciano "pone me", difundido en el Renacimiento por influencia de un famoso soneto de Petrarca. Es una canción pastoril porque la mayoría de sus versos están puestos en boca del pastor Albino, que se lamenta de la ausencia de su amada Delia. El pastor en cuestión se reafirma en su amor porque se imagina sintiéndolo en cuerpo y alma en los lugares más remotos y solo en alma en los reinos de la muerte:

Y aún ya de su prisión mortal y obscura

El espíritu mío desatado,

Doquier que le llevare mi aventura,

Ora al Estigio o al Eliseo prado,

Siempre quedará firme en su deseo,

Siempre te adorará,

Siempre [Delia] dirá,

Si no se pierde el paso del Leteo,

La fe que aquí se cría (vv. 82-90) (Figueroa, 1989: 189-191).

En esos mismos años Gutierre Cetina recuerda también el verso de Sannazaro para desear precisamente que su alma, al cruzar el Leteo, olvide la vida terrenal, como también había hecho la de Ausiàs March en otros versos que el sevillano ha tomado como modelo principal:

Fuego queme mi carne y por incienso

Baje el humo a las almas del infierno;

Pase la mía aquel olvido eterno

De Lete porque pierda el bien que pienso (XV, 1-4) (Cetina, 1981: 92 y 2014: 238).

Cetina demuestra conocer el verso del poeta napolitano al adoptar alguna de sus palabras claves (especialmente los verbos "pasar" y "perder") para alejarse de su modelo principal, los versos que March compuso con la misma ocasión de dejar de pensar en el amor que lo ha atormentado en vida: 
Mon espirit trespàs de Lete 1 flum

perquè de res de aquest món no pens! (CII, 139-140) (March, 1987: 450).

\section{Otras versiones del amor más allá del Leteo}

En los Dialoghi d'amore, publicados en Roma en 1535 pero seguramente ya compuestos en 1502, León Hebreo también, como Sannazaro, contempla la posibilidad de que el alma, al pasar el río Leteo, no haya conseguido olvidar su vida terrenal y siga experimentando las mismas sensaciones que antes:

Io non mi ricordo averti promesso altra cosa se non d'amarti e di partire li tuo sdegni, fin a tanto che Caronte mi passi il fiume de l'oblivione, e oltra di ciò se da la parte di là l'anima si truova con qualche sentimento, non sarà mai spogliata d'affezione e mártires (Hebreo 2003: en línea).

En 1598, el inca Garcilaso de la Vega traduce el texto con una precisión y literalidad encomiable:

No me acuerdo haberte prometido otra cosa que amarte y padecer tus desdenes hasta que Carón me pase el río del olvido; de más de esto si el ánima allá en la otra parte se halla con algún sentimiento no estará jamás despojada de afición y martirio (Hebreo 1590: 60) $)^{5}$.

Otro poeta italiano, amigo de Garcilaso, con quien convivió en Nápoles entre 1532 y 1536, recreó ya más libremente el verso de su compatriota en varios de sus poemas. Lo hizo, por ejemplo, en un soneto al que su editor puso el epígrafe muy significativo de "Ha amato ed amerà sempre lei, suo primo ed ultimo amore, sin anche dopo la morte" para dejar constancia de que la llama de su amor, viva en la ceniza de sus huesos tras la muerte, alcanzará la otra orilla del río Leteo:

Io arsi per voi, donna, e per voi ardo, E per voi arderò, quanto ch'io viva, E giunga il corso de la vita a riva

Più tosto ch'io non bramo, o giunga tardo.

Né d'altro raggio, che del vostro sguardo,

Scaldar può l'alma, d'altro obbietto schiva:

Se voi non avea il mondo, ella sen giva

Senza sentir d'amor face né dardo.

Voi, vita e morte mia, foste il primiero

Foco che m'arse, anzi che meco nacque

\footnotetext{
${ }^{5}$ Este pasaje, en la traducción de Garcilaso el Inca, lo aduce Sobejano (1985: 638) para ilustrar la confusión habitual entre los autores del siglo de oro entre la laguna Estigia y el río Leteo.
} 
Prima di voi; voi l'ultimo sarete.

E dopo il cener di quest'ossa spero

Per far, mal grado de le nubi d'acque,

Vive le fiamme mie di là di Lete (LXVIII) (Tansillo, 1996: 95-96 y 2011: 394-395).

Luigi Tansillo, que así se llama nuestro poeta, emplea la imagen (que después retoman Marino y Quevedo) de la llama que recorre las aguas del olvido sin sufrir ningún tipo de mengua. En otro soneto, perteneciente al ciclo dedicado a Luisa Puccio, con la que se casó en 1550, expresa el deseo de que esa llama en la que ha ardido siempre, cuando joven y cuando viejo, no se apague en las ondas del famoso río del Averno:

Io priego Amor, ch'al biondo e al bianco pelo, arder mi faccia, e quand'io serò spento,

non spenga onda di Lete l'ardor mio (12-14) (Tansillo, 196: 283 y 2011: 632-633).

En el epígrafe su autor ha especificado que el soneto lo ha compuesto Tansillo con motivo de haberle regalado un abanico a la que había de ser su esposa para mitigar el calor que podía abrasarla.

Gutierre de Cetina tradujo muy claramente el primero de los tres sonetos citados de Tansillo; en algunos versos lo sigue al pie de la letra, pero en otros, en cambio, introduce cambios significativos (omite, por ejemplo, la alusión a las cenizas):

Por vos ardí, señora, y por vos ardo,

$\mathrm{Y}$ arder por vos mientras viviere espero,

O contraste el deseo el hado fiero,

O sea favorable al bien que aguardo.

Tan a lo vivo ha penetrado el dardo

De Amor, que cuando menos bien os quiero,

Por vos deseo morir, y por vos muero,

Y por vos sola de morir me guardo.

Vos el primer ardor fuisteis al alma;

Vos último seréis en la última hora;

$\mathrm{Y}$ creed a mi fe lo que os promete.

Bien podrá de mi muerte haber la palma,

Mas después se verá, cual es ahora,

Pasar el fuego mío de allá de Lete $^{6}$ (Cetina, 1981: 182 y 2014:

417-418).

\footnotetext{
${ }^{6}$ Para corregir la hipermetría del verso hay que leer "mio" como de una sola sílaba; Cetina traduce literalmente "di là" ("de allá") cuando en castellano debería haber escrito "más allá de".
} 
Juan de Arguijo, buen amigo de Lope de Vega, se refiere a la "llama" no de amor sino de la fama (la de Aquiles) que el Leteo no podrá extinguir nunca:

O gloria de la Grecia, claro fuego cuya llama las sombras de Leteo no bastan a encubrir, ni su trofeo borrar podrá jamás olvido ciego (Arguijo 1971: 109).

Otro poeta napolitano, sólo unos años más joven que Góngora y Lope, Giovan Battista Marino, incluyó en la sección "amorose" de la primera parte de La Lira (Nápoles, 1614) un soneto en que imita de forma muy evidente (sobre todo en el arranque) uno de los de Tansillo que hemos analizado antes (lleva como título "Promette alla sua donna perpetuo amore"):

I'arsi et ardo, e la celeste e pura face, ond'Amor di te l'alma m'accese, sì forte nel mio cor, donna, s'apprese, che non fia mai per volger d'anni oscura.

E se fia pur (sì come vuol Natura) eterna in ciel la mia stella cortese, questa, che da' suoi raggi in me discese, eterna ancor sarà, felice arsura.

Fortuna non potrà, tempo né loco spegner favilla del mio 'ncendio; e pria vedrai quest'ossa incenerir, che ' 1 foco.

Anzi di là dal fiume, ove s'oblia ogni cosa mortal, mi parrà poco viva e chiara portar la fiamma mia (Marino 2003: en línea).

Pero Marino no sólo se ha inspirado en el primer verso de Tansillo, sino que también se ha apropiado de la doble imagen final: la incineración de los huesos y la llama que llega intacta a la otra orilla del río Leteo. Incluso ha llegado a repetir las mismas expresiones: "il cener di quest'ossa" y "quest'ossa incenerir", o "di là di Lete" y "di là del fiume", o "vive le fiamme mie" y "viva... la fiamma mia".

Entre sus Rime (Venecia, 1530), Pietro Bembo incluyó unos cinco sonetos, antes de la parte in morte, en los que expresaba su enérgica decisión de renunciar definitivamente al amor. El primero de los cinco, que compuso en el verano de 1528, coincidiendo con el nacimiento de su hija Elena, lo dirigió a su amigo Bernardo Capello. Es un soneto con el que dio origen a otros, como el de Luigi Tansillo, Gutierre de Cetina y Marino, con los que coincide por empezar de la misma manera y por introducir al final una referencia al río Leteo:

Arsi, Bernardo, in foco chiaro e lento

Molt'anni assi felice, e, se 'l turbato 
Regno d'Amor non ha felices tato,

Tennimi almen di lui pago e contento.

Poi, per dar le mie vele a miglior vento, Quando lume del ciel mi s'è mostrato,

Scintomin del bel viso in sen portato,

Sparsi col piè la fiamma, e non men' pento.

Ma l'imagine sua dolente e schiva

M'è sempre inanzi, e preme il cor sì forte,

Ch'io son di Lete omai presso a la riva.

S'io ' 1 varcherò, farai tu che si scriva

Sovra 'l mio sasso, com'io venni a morte,

Togliendomi ad Amor, mentr'io fuggiva (Bembo, 1992: 600-601).

Bembo, en cualquier caso, da una versión si no contraria bastante diferente a la de los sonetos que sirvió de modelo. Confiesa al amigo que después de haber amado muchos años ha decidido dejarlo de hacer (los dos primeros cuartetos); admite a continuación (en el primer terceto) que esa imagen (la del rostro de la amada) de la que creía haber liberado a su corazón la tiene siempre delante, de modo que le oprime tan fuerte el corazón, que está a punto de cruzar el río Leteo. Si es el caso que logra recorrer sus aguas pretende que en el epitafio de su tumba se escriba cómo la muerte lo sorprendió mientras estaba huyendo del amor. Si se refiere al río del olvido es menos como tal que como sinónimo de la muerte: da a entender que amor le asfixia el corazón de tal manera que lo lleva al borde de la muerte. Sólo quiere dejar constancia de que halló la muerte cuando estaba intentando liberarse del amor (y que de algún modo aún no lo había conseguido).

El poeta sevillano Fernando de Herrera se dedicó a traducir más que imitar el soneto de Bembo limitándose a cambiar solo unos cuantos versos y, por supuesto, el nombre del interlocutor: Fernando por Bernardo. No llegó a publicarlo en vida sino que lo dejó para la parte final del libro primero de Versos (Sevilla, 1619):

Ardí, Fernando, en fuego claro i lento,

Muchos días dichoso, i si el turbado

Reino d'Amor no tiene fiel estado,

Entre los presos yo viví contento.

Después, por dar la vela'l blando viento,

Cuando la luz d'el cielo s'ha mostrado,

D'aquel estrecho nudo desatado,

Esparcí con el pie la llama'l viento.

Mas la imagen d'Amor airada i fiera

Siempre delante trae a mi enemiga,

Tal, qu'estoi a la orilla de Letheo.

$\mathrm{Si}$, muriendo, passare su ribera,

Escríbase en mi mármol que huía,

I que murió luchando mi deseo (Herrera, 1985: 614). 
En una primera y rápida lectura del soneto, se aprecia claramente la literalidad con que lo adapta el sevillano. Si lo volvemos a leer podremos detectar una pocas, pero significativas, diferencias con respecto a su modelo. En el primer cuarteto, Herrera sólo introduce un ligero cambio en su último verso: interpreta "tennimi almen di lui pago e contento" ("túvome al menos de él satisfecho y contento") como "entre los presos yo viví contento"; en el segundo, modifica también (aunque muy levemente) el último verso y especialmente el tercero: ha convertido "e non men' pento" ("y no me arrepiento") en "'l viento" (y al hacerlo incurre en una rima idéntica con "viento") y "scintomi del bel viso in sen portato" ("desligome del bello rostro llevado en el corazón") en "d'aquel estrecho nudo desatado". En los tercetos se desmarca un poco más del soneto italiano al suprimir la causa más directa y física por la que en el modelo el poeta se halla cerca de la orilla del Leteo: "e preme il cor sì forte" ("y oprime el corazón tan fuerte"). Es precisamente en el verso final cuando más se aleja del soneto en el que se inspira al optar por uno con más de un sentido: "i que murió luchando mi deseo". Puede estar dando a entender, al igual que Bembo, que en el momento de su muerte física (al estar atravesando el Leteo) estaba esforzándose por extinguir el deseo. Pero también puede estar diciendo que su deseo se extinguió luchando con las aguas del río para sobrevivir al olvido y a la muerte.

Benedetto Varchi, no mucho más joven que Garcilaso, también compuso un soneto del estilo de los anteriores, que publicó en la segunda parte de sus Rime (Florencia, 1557). Como Tansillo y Cetina, empleó las dos formas del verbo "arder", tanto en pretérito indefinido como presente, pero no en el primer verso sino en el octavo; y como Bembo y Herrera, lo dirigió a un amigo (en su caso el también poeta y traductor Annibal Caro). Al igual que los cuatro, introdujo la obligada referencia al río Leteo (pero lo hizo bastante antes que los demás):

Caro Annibal, né cervi mai, né damma

Con tal disìo cercar fiume, né fonte,

Com'io quegl'occhi santi e chiara fronte,

Che solo a bei pensier l'anime infiamma;

Conosco i segni dell'antica fiamma,

Che fece le mie voglie ardite e pronte

Di schivar Lete e poggiar l'alto monte

Onde arsi ed ardo tutto a dramma a dramma.

Perch'io non so pensar qual parte mia

Possa, né perch'io brami, o come spere

Dar luogo a nuovo fuoco e piaga omai.

Eppur nuova virtute e leggiadria

Di viva petra e più bella che mai

Lucesse, dolce ognor m'incende e fere (Varchi 2006: en línea). 
Varchi alude a una cumbre en la que afirma haber ardido y seguir ardiendo tras superar el río del olvido. Parece dar a entender que su llama no ha cruzado las aguas del Leteo sino que las ha esquivado para no someterla a sus efectos amnésicos. Si bien no otorga un significado concreto a "l'alto monte" en el que su llama se ha conservado intacta, podría haberlo considerado como símbolo de un amor espiritual. Afirma que los ojos santos y la frente clara que desea con igual sed que los ciervos las fuentes solo inspiran en su alma bellos pensamientos. No parece sentir un amor tan físico como el tipo de amor que los poetas a quienes ha imitado habían reconocido sentir.

En el Libro delle Rime (Mantua, 1591), recogidas y ordenadas por sí mismo, Torquato Tasso incluyó un soneto al que dio un título con el que lo presentó como ocasional: "Per una dama che in chiesa dimandò d'un cavaliere assente"; en sus versos no alude para nada al caballero en cuestión pero sí es verdad que en el cuarteto inicial le pregunta a su dama si en la iglesia se había acordado de él. En el resto del poema, reelabora el famoso tópico horaciano "pone me" para garantizarle que esté donde esté siempre la llevará impresa en el alma y que ya no temerá las aguas del olvido (dando a entender que después de recorrerlas no la olvidará):
Io per mudar contrada, o nel Levante, Donde si mostra la vermiglia Aurora, O dove cade il sole, e perch'io mora, O torni al ciel, qual Pellegrino errante, Terrò di voi memoria, e voi nell'alma In cui l'impresse Amor di propria mano, Ni giammai temerò l'acque di Lete (Tasso, 1821: 198).

En la Parte II de las Rimas (Madrid, 1609), Lope de Vega incluye uno de los sonetos dedicados a Micaela Luján (Lucinda) en el que sin duda recuerda los versos de Sannazaro. Le pide a su amada que la muerte les sorprenda abrazados como lo están las yedras en los troncos de los álamos para de ese modo atravesar también el Leteo y amar más allá del olvido:

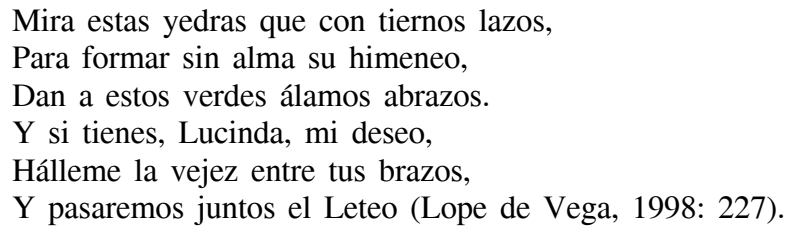

No tendría sentido que Lope pensara en dejar de experimentar el deseo por Lucinda al surcar las aguas del olvido si pretende morir tan estrechamente abrazado a su cuerpo: si es el amor o el deseo (la yedra adherida al tronco del 
álamo es su símbolo más notorio) el que une a los dos amantes en semejante abrazo ese mismo amor o deseo los seguirá manteniendo unidos después del olvido (si así no fuera dejarían de estarlo y se separarían).

En otro extraordinario soneto, también dirigido a Lucinda, Lope de Vega no pretende más propósito que amarla y verla para de ese modo convertirla en una especie de Beatriz (no en Laura) que al alabarla en sus versos alcance el Paraíso. Con ellos pero también con el amor que los ha inspirado ("Mis lágrimas..., mis suspiros") se considera indemne al paso del tiempo y al olvido:

Ya no quiero más bien que sólo amaros,

Ni más vida, Lucinda, que ofreceros

La que me dais cuando merezco veros,

Ni ver más luz que vuestros ojos claros.

La pluma y lengua respondiendo a coros

Quieren al cielo espléndido subiros,

Donde están los espíritus más puros;

Que entre tales riquezas y tesoros

Mis lágrimas, mis versos, mis suspiros

De olvido y tiempo vivirán seguros (Lope de Vega, 1998: 295).

En Canta sola a Lisi, publicada como segunda parte de la musa Euterpe en el Parnaso español (Madrid, 1648), Francisco de Quevedo introduce dos sonetos en los que también plantea el tema del amor (en sus diversas formas, incluida la de la llama) que supera las barreras de la muerte y el olvido. En el primero de los dos, parece combinar los versos de la elegía de Propercio con otros del soneto de Marino:

De esotra parte de la muerte dura,

Vivirán en mi sombra mis cuidados,

Y más allá de el Lethe mi memoria.

Triunfará de el olvido tu hermosura;

Mi pura fe y ardiente, de los hados;

Y el no ser, por amar, será mi gloria (Quevedo, 1998: 203).

Cuando escribió "más allá de el Lethe [vivirá] mi memoria” pensaba en el verso de Marino "di là del fiume... viva... portar la fiamma mia", sin olvidarse del de Sannazaro "nel passar di Lete amor non perdesi"; y cuando compuso "de esotra parte de la muerte dura...", "Triunfará de el olvido tu hermosura" y "Mi pura fe y ardiente, de los hados" tenía en mente el verso de Propercio "traicit et fati litora magnus amor". Para el último verso postuló la mejor versión de "la inmortalidad de la nada" (es el título de un poema de Ángel González): la nada que, gracias al amor, llega a ser inmortal.

En el segundo de los sonetos, el famoso "Cerrar podrá la postrera/ sombra", 
el madrileño vuelve repetir la misma imagen del río Leteo mezclada con la del nadador por excelencia de la literatura, el del fogoso Leandro que llega a la otra orilla del Helesponto tan encendido como cuando se había arrojado a sus frías aguas:

Mas no de essotra parte en la ribera
Dejará la memoria donde ardía.
Nadar sabe mi llama el agua fría
Y perder el respeto a ley severa (Quevedo, 1998: 227).

En los dos primeros versos del cuarteto, Quevedo se hace eco del verso de Sannazaro al asegurar que su alma no se desprenderá de su parte sensitiva, la memoria en la que arde o conserva su amor, cuando haya alcanzado la parte opuesta del río (es lo que debía haber hecho el alma intelectiva en su travesía por el purificador Leteo); en los otros dos, nuestro poeta ha tenido muy presente los versos de Tansillo y Marino al convertir la llama en metáfora del amor que no se apaga en contacto con las aguas frías del olvido.

Para cerrar esta primera parte de mi trabajo me voy a referir a poetas que no pretenden recrear directamente el verso de Sannazaro pero que en última instancia acaban tratando el tema del amor y la vida más allá de la muerte y el olvido. Garcilaso es uno de esos poetas que no adapta claramente el verso en cuestión pero que hace también un uso especial del río Leteo. En su última égloga, se dirige a una María (María Osorio o María de Cardona) a quien asegura la inmortalidad por comprometerse a alabar su hermosura y su ingenio cuando muerto ya pase las aguas del olvido:

$\mathrm{Y}$ aun no se me figura que me toca

Aqueste oficio solamente en vida,

Mas con la lengua muerta y fría en la boca

Pienso mover la voz a ti debida;

Libre mi alma de su estrecha roca,

Por el Estigio lago conducida,

Celebrando t'irá, y aquel sonido

Hará parar las aguas del olvido (Garcilaso, 2007: 309).

Al confundir la laguna Estigia con el río Leteo, Garcilaso no establece la separación virgiliana y dantesca entre la muerte y el olvido. En el poeta en el que se inspira ha leído que el río a cuyas aguas las bacantes arrojan la cabeza de Orfeo no es ninguno del infierno sino el río Hebro de Tracia. Pero a diferencia del mítico músico no se limitará a pronunciar el nombre de su amada sino a escribirle versos en los que pueda seguir alabando todas sus virtudes. Con esos versos pretende detener las aguas del Leteo para evitar la llegada a la otra orilla y así el olvido definitivo de María. Desafía también las leyes de la 
naturaleza pero de modo distinto al propuesto en la Arcadia. El poeta napolitano alude a la posibilidad de atravesar el río Leteo sin padecer los efectos que sobre el alma habitualmente operan sus aguas; el toledano, en cambio, para no sufrirlos, no halla más solución que hacerlas parar y no recorrerlas hasta su final. Parece tener claro que el arte (largo como lo imagina el famoso aforismo atribuido a Hipócrates) puede sobrevivir a la muerte pero nunca al olvido.

El toledano para esos versos sin duda se ha inspirado directamente en otros que hemos citado arriba del Cariteo. El poeta barcelonés se imaginaba también en la muerte invocando, al igual que Orfeo, el nombre de su amada para con su música detener las aguas del Leteo y no llegar de ese modo a recorrerlas hasta la otra orilla:

Ma s'alcuna ombra in ciel o negli abissi

Riman di poi l'acerba morte mia,

Non girà mai tra l'anime quiete,

Anzi chiamando il nome in ogni via

Di lei, per cui, morendo, al mondo vissi,

Non passarà la negre onde di Lete.

Garcilaso podría, siguiendo a su modelo, diferenciar la laguna Estigia del río Leteo: su alma atravesaría primero las aguas de la muerte y después las del olvido (y sólo con su poesía detendría las segundas para evitar sus efectos amnésicos). El Cariteo al principio se refiere a los lugares que la suya podría ocupar tras su muerte: el paraíso o el infierno; al descartar el primer lugar, el propio de las "almas quietas", sólo halla un modo de alejarse de él: la detención de las aguas del río Leteo (y eso sólo puede conseguirlo al pronunciar el nombre de su amada mientras empieza a atravesarlas).

Muchos poetas de Renacimiento y del Barroco imitaron esos versos del toledano al suponer que Orfeo en su descenso al infierno para recuperar a su esposa Eurídice llegó con su música o con su llanto a detener las aguas del olvido. Lope de Vega, por ejemplo, en sus Rimas (Madrid, 1609), incluye varios sonetos en que menciona ese milagro del músico de Tracia. En el último que reproduce al final de volumen y que titula "Camila Lucinda", pone voz a su amada para que desde el más allá, habiendo cruzado el Leteo, al igual que Eurídice, recuerde a su poeta (el Orfeo español) no sólo deteniendo con su lira las aguas del olvido sino también haciendo a los dos famosos (poeta y amada) con unos versos (los de las $R i$ mas) tan inmortales como el amor que los ha inspirado:

Cuando como otra Eurídice, teñido

De sangre el blanco pie, mas no el deseo

De las injustas quejas de Aristeo,

Pasado hubiera el agua del olvido, 
Al arco de tu lira detenido

Y en blanda paz sus almas el Leteo,

Vieran mis ojos, español Orfeo,

Segunda vez el resplandor perdido.

¡Oh clara luz de amor que el hielo inflama!;

Su curso el tiempo en estos versos mida;

Sirvan de paralelos a su llama.

Por ellos corra mi memoria asida,

Que si vive mi nombre con tu fama,

Del alma igualará la inmortal vida (Lope de Vega, 1969: 268-269).

En un soneto satírico en el que rinde homenaje a Garcilaso, a quien al final apela llamándolo Salicio, presenta a Orfeo bajando a los infiernos para, tras detener las aguas de Leteo con sus lágrimas, poder ver con su deseo a Eurídice (es el mismo deseo que sentía en vida porque el descenso al Hades lo hace vivo y no muerto, en carne y no en sombra):

A las ardientes puertas de diamante,

Coronado del árbol de Peneo,

Mostraba en dulce voz llorando Orfeo,

Que allí puede llorar un tierno amante.

Suspendidas las furias de Atamante,

Y parado a sus lágrimas Leteo,

En carne, que no en sombra, su deseo

Vio su querida Eurídice delante (Lope de Vega, 1998: 289).

En su égloga Amarilis (Madrid, 1633), Lope de Vega narra en casi mil quinientos versos su historia de amor — la más intensa que vivió- con Marta de Nevares, a quien llevaba casi treinta años. Al final lamenta su muerte y se imagina al olvido enamorado otra vez para poder también llorar junto a la propia muerte:

Lloró cuanto es amor; hasta el olvido

A amar volvió, porque llorar pudiera,

$\mathrm{Y}$ es locura de mi amor tan fuerte

Que pienso que también lloró la muerte (Lope de Vega, 1991: 227).

Lope lleva mucho más lejos el dilema que plantea el famoso verso de Sannazaro. No piensa en la posibilidad de que el amor sobreviva al olvido (traspase sus aguas sin ser víctima de sus efectos), sino que experimente unos sentimientos que en teoría habría de extinguir por completo. Es obvio que nuestro poeta está pensando en la representación mitológica del olvido como un río, al que debe suponer con el mismo aspecto humano con que suele presentarlo la tradición clásica. Es sólo de ese modo como puede personificarlo con esa capacidad para el amor y el llanto. Al caracterizarlo también reincidente en 
el amor ("a amar volvió") podría esta aludiendo a remotas mitologías en que lo hubiese conocido, en efecto, enamorado de alguna ninfa. El río Alfeo lo estuvo, por ejemplo, de Aretusa, cuando la vio bañarse en sus aguas.

\section{Breve apéndice del siglo XVIII}

Un poeta que representa una clara transición entre el Neoclasicismo y el Romanticismo, Gaspar María de Nava Álvarez, más conocido literariamente por conde de Noroña, compuso una oda, publicada en su edición de Poesías (Madrid, 1799), en que claramente imita los versos de Garcilaso:

Oh tú, que pulsas con marfil agudo

La cítara sonante, y cual Orfeo

Suspendes la corriente del Leteo

Y cuanto arrebatar su dicha pudo (Álvarez de las Asturias, 1871: 439).

El conde de Noroña se está dirigiendo a un poeta que ha elogiado en exceso al pastorcillo Fenicio en lugar de dedicar sus versos "a asuntos más sublimes y gloriosos" porque considera que de ese modo ha desperdiciado su talento. Alude también al río Leteo como sinónimo de la muerte en general porque lo hace responsable de haberle arrebatado a Eurídice ("su dicha").

En uno de sus poemas persas, pensado para su amada muerta Leyla, utiliza el condicional que recuerda el tan característico de Sannazaro al final de su Arcadia; no menciona explícitamente el río Leteo porque, como acabamos de ver, suele confundirlo con la muerte:

Si después de la muerte todavía

Se encuentran nuestras voces dolorosas,

Y bajo las elevadas duras losas

Abrasa el pecho el fuego que solía,

Prosiga el eco de la angustia mía;

$\mathrm{Y}$ las verdes colinas, que envidiosas

Dividen nuestras tumbas silenciosas,

Le aumenten y repitan a porfía,

Para que sea al punto conducido

A Leyla en alas del piadoso viento,

Hiriendo con amor su tierno oído:

Así tendré al morir este contento

Que, aunque me halle ya a polvo reducido,

Se goce Leyla con mi triste acento (Álvarez de las Asturias, 2003: 133).

El conde de Noroña espera seguir amando después de la muerte para poderle componer versos a su amada Leyla y hacérselos llegar a su tumba: en parte 
también en este soneto recuerda los versos de la égloga III de Garcilaso (piensa "mover la voz a ti debida" a Leyla tras cruzar la frontera de la muerte).

Otro poeta de la misma época, Manuel María Arjona, podía recordar el verso de Sannazaro (quizá a través de Francisco de Figueroa y Juan de Arguijo). El poeta de Osuna, de la provincia de Sevilla, en 1788, puso en boca del difunto Carlos III unos versos que lamentan su muerte ocurrida ese año:

Contra la avara furia del Leteo

Mi nombre ilustre veo,

Que los siglos trasciende (Arjona, 1871: 14)

Arjona sin duda recuerda la elegía que Francisco de Figueroa dedica a la muerte del primogénito de Felipe II, Carlos de Austria, y que también (aunque no toda ella) atribuye al propio difunto. No es el amor sino la fama o el nombre ilustre la que o el que puede sobrevivir al olvido.

En unas endechas de Aletino a Adelaida, Arjona podía estar teniendo en cuenta el famoso idilio atribuido a Teócrito (muy difundido en traducciones latinas en el siglo XVII) al considerar la conveniencia de que el amor de su personaje lo apaguen las aguas del río Leteo:

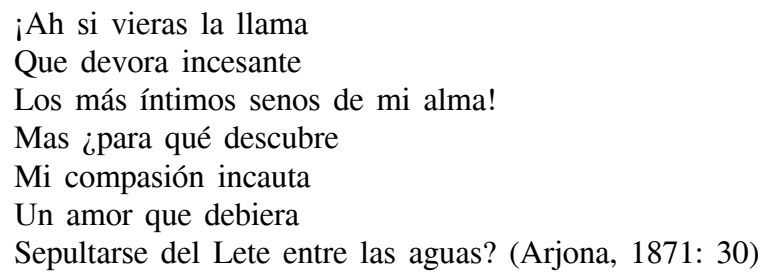

Aletino parece reproducir el mismo planteamiento que el anónimo amante del idilio griego: al ser víctima de un amor tan intenso, que lo devora, piensa que la única solución para dejar de sufrir es anegarlo en el río del olvido (y al expresar semejante propósito da a entender que aunque se lo beba toda seguirá experimentándolo y padeciendo).

En otro de sus poemas, Arjona vuelve a aducir el Leteo como el lugar en que se ahogan las penas para olvidarlas completamente. Lo hace en el momento en que los dos personajes de su obra, Licon y Roselia, se aman mutuamente y celebran el himeneo:

Venciste, Amor, y en brazos de Himeneo

Roselia con Licon se goza unida.

Vuelan las negras penas al Leteo,

Y alza un ara al amor... (Arjona, 1871: 29) 
John Carey estaba seguro de conservar en sus cenizas el bello nombre de su amada Irene para seguir invocándolo y recordándolo en la muerte y seguramente también en el olvido. Cuando el poeta inglés eligió el sustantivo "paz" para expresar el sentimiento de sus cenizas pensó en los efectos purificadores del río Leteo, tal como los había definido Virgilio en uno de los versos de la Eneida (VI, 713-715):

Animae, quipus altera

fato corpore debentur, Lethaei ad fluminis undam

securos latices et longa oblivia potant (Virgilio 1959: 190).

(las almas, a las que el hado debe otro cuerpo, beben en las ondas del río Leteo aguas que otorgan la paz, la tranquilidad, y largos olvidos)

En uno de los sonetos amorosos de Canta sola a Lisi Quevedo pide la muerte para hallar el descanso que no ha tenido en vida: incurre en la paradoja de reconocer haber sentido dolor a la vez que haber amado la virtud. Termina con un verso que podía haber inspirado el de John Carey:

$\mathrm{Y}$ ya que supe amar esclarecida

Virtud, siempre triunfante, siempre hermosa,

Tenga paz mi ceniza presumida (Quevedo, 1998: 256).

El poeta madrileño se considera acreedor de la paz que otorga el olvido no por el amor pasional que tanto lo ha atormentado sino por el amor neoplatónico que también parece haber experimentado: el primer tipo de amor, como ha explicado en otros sonetos que hemos analizado antes, le garantiza la perpetuación del dolor en las cenizas.

John Carey, por su parte, ha jugado con esa paz que conceden las aguas del Leteo para admitir que tras bebérselas todas no obtendrá más paz para la eternidad que el bello nombre de su amada (para él la eternidad sí tenía amor): nunca antes había conocido otra paz ni tampoco después. En un solo verso condensó una larga tradición literaria y el gran amor que sintió por Irene, sin duda mucho más largo que el olvido.

\section{BIBLIOGRAFÍA}

Arguijo, Juan de (1971): Obra poética, Stanko B. Vranich (ed.), Madrid, Castalia. Arjona, Juan (2013): La Tebaida de Publio Papinio Estacio, en Pere-Enric Barreda (ed.), Lemir, $<$ uv.es/lemir/Textos> [fecha de consulta del 20/03/2013].

Arjona, Manuel María (1871): Poesías, Leopoldo Augusto Cueto (ed.), Madrid, Rivadeneyra. Ausonio, Décimo Magno (1971): Opere, Agostino Pastorino (ed.), Torino, Unione TipograficoEditrice Torinese. 
Bembo, Pietro (1992): Prose e Rime, Carlo Dionisotti (ed.), Torino, Unione Tipografico-Editrice Torinese.

Blecua, Alberto (2006): “¿Signos viejos y signos nuevos? ('Fino amor' y 'religio amoris’ en Gregorio Silvestre)”, en Signos viejos y nuevos. Estudios de historia literaria, Barcelona, Crítica.

Boccaccio, Giovanni (1987): Elegia di Madonna Fiammetta, Maria Pia Mussini Sacchi (ed.), Milano, Mursia.

Boccaccio, Giovanni (1990): Decameron, vol. I, Vittore Branca (ed.), Torino, Einaudi.

Boscán, Juan (1992): Obra completa, Carlos Clavería (ed.), Madrid, Cátedra.

Camoens, Luis (1621): Rimas. Primera parte, Lisboa.

Cariteo [Gareth, Benedetto] (1892): Le rime secondo le due stampe originali, Erasmo Pèrcopo (ed.), Napoli, Tipografia dell'Accademia delle Scienze.

Castro De Castro, José David (1998): La traducción latina de los “Idilios” de Teócrito de Vicente de Mariner, <interclassica.um.es/investigacion/tesis> [fecha de consulta: 20/03/2013].

Cetina, Gutierre (1981): Sonetos y madrigales, Begoña López Bueno (ed.), Madrid, Cátedra.

Cetina, Gutierre (2014): Rimas, Jesús Ponce Cárdenas (ed.), Madrid, Cátedra.

Daniello, Bernardino (1568): L'espositione sopra la sua Comedia dell'Inferno, del Purgatorio $e$ del Paraiso, Venezia, en Darmouth Dante Project <dante.darmouth.edu $>$ [fecha de consulta: 03/03/2013].

Dante Alighieri (1976): La Divina Commedia, Daniele Mattalia (ed.), Milano, Rizoli.

Figueroa, Francisco de (1988): Obra, Christopher Maurer (ed.), Madrid, Istmo.

Figueroa, Francisco de (1989): Poesía, Mercedes López Suárez (ed.), Madrid, Cátedra.

Fox, Denis, Juan Manuel Morcillo y Benedetto Mondolfo (1983): “Tres notas bio-bibliográficas sobre John Carey", Revista de Literatura. Fragments, I, pp. 19-24.

Hebreo, León (2003): Dialoghi d'Amore, en Biblioteca Italiana, <bibliotecaitaliana. it> [fecha de consulta: 05/03/2013].

Herrera, Fernando de (1985), Poesía castellana original completa, Cristóbal Cuevas (ed.), Madrid, Cátedra.

Inca Garcilaso de la Vega (1989): La traducción del Indio de los tres Diálogos de amor de León Hebreo, Madrid, Pedro Madrigal, 1590, edición facsímil, con introducción de Miguel de Burgos Núñez, Sevilla, Padilla Libros.

López Pozal, Sagrario (2005): "La difusión y recepción de la Antología griega en el siglo de oro", en Begoña López Bueno (dir.), VII Encuentro Internacional sobre Poesía del Siglo de Oro (Universidad de Sevilla, 20-22 de noviembre de 2003). En torno al canon: aproximaciones y estrategias, Sevilla, Grupo Paso, pp. 15-67.

March, Ausiàs (1997): Obra completa, Robert Archer (ed.), Barcelona, Barcanova.

Marino, Giovan Battista (2003): Rime amorose, < bibliotecaitaliana.it> [fecha de consulta: 05/03/ 2013].

Martos, Josep Lluís (2001): Fonts i cronologia les proses mitològiques de Joan Roís de Corella, Alicante, Universidad de Alicante.

Martos, Josep Lluís (2005): “'Con li suoi vestimenti asciugare il morto viso della salata acqua, e bagnarlo di molte lagrime': la Fiammetta en el Leànder y Hero de Roís de Corella”, Caplletra. Revista Internacional de Filologia, 39, pp. 257-276.

Marullus, Michael (2012), Poems, Charles Fantazzi (ed.), Cambridge, Harvard University Press.

Morros, Bienvenido (2013), "La moralización del Leandro de Boscán: origen, interpretación y difusión de una fábula”, Studia Aurea, 7, pp. 199-267.

Nava Álvarez de las Asturias, Gaspar María de (1871): Poesías, Madrid, Rivadeneyra.

Nava Álvarez de las Asturias, conde de Noroña, Gaspar María de (2003): Poesías asiáticas, Santiago Fortuño (ed.), Madrid, Hiperión. 
Olivares, Julián (1995): La poesía amorosa de Francisco de Quevedo: estudio estético y existencial, Madrid, Siglo XXI de España Editores.

Ovidio (1975): Tristia. Ex Ponto, Arthur Leslie Wheeler (ed.), Cambridge/ London, Harvard University Press/ William Heisemann Ltd.

Ovidio (1983): Metamorfosis, Antonio Ruiz de Elvira (ed.), con texto, notas e índice de Bartolomé Segura Ramos, vol. III, Madrid, CSIC.

Propercio (1963): Elegías, Antonio Tovar y María T. Belhore Mártire (eds.), Barcelona, Alma Mater.

Pseudo-Teócrito (1977): The Greek Bucolic Poets, en J. M. Edmonds (ed.), London, Harvard University Press.

Pujol, Josep (2013): "Noves fonts ovidianes, pràctiques escolars i Boccaccio al Leànder i Hero de Joan Roís de Corella", Cultura Neolatina, 73, pp. 153-183.

Quevedo, Francisco (1998): Un Heráclito cristiano, Canta sola a Lisi y otros poemas, Lía Schwartz e Ignacio Arellano (eds.), Barcelona, Crítica.

Roís De Corella, Joan (1983): Obra profana, Valencia, Edicions Tres i cuatre.

Roís de Corella, Joan (2001): Les proses mitològiques de Joan Roís de Corella, Josep Lluís Martos (ed.), Alacant/ Barcelona, Institut Interuniversitari de Filologia Valenciana/ Publicacions de l'Abadia de Montserrat.

Samosata, Luciano de (2004): Obras, edición bilingüe por Manuela García Valdés, vol. VI, Madrid, CSIC.

Sannazaro, Jacopo (1990): Arcadia, Francesco Erspamer (ed.), Milano, Mursia.

Sebastián Perdices, Irene y Bienvenido Morros (2013): "La Favola di Leandro e d'Ero de Bernardo Tasso: fuentes y contaminaciones con otras fábulas", Studi Rinascimentali, 11, pp. 173-198.

Serés, Guillermo (1996): La transformación de los amantes. Imágenes del amor de la antigüedad al siglo de oro, Barcelona, Crítica.

Sidonia, Antipatro de (1970): The Greek Anthology, en W. R. Paton (ed.), Cambridge/ London, Harvard University Press/ William Heinemann Ldt.

Silvestre, Gregorio (1939): Poesía, Antonio Martín Ocete (ed.), Granada, Publicaciones de la Facultad de Letras.

Sobejano, Gonzalo (1985): "Aspectos del olvido en la poesía de Quevedo", en Homenaje a José Manuel Blecua, Madrid, Gredos, pp. 635-641.

Striggio, Alessandro (1607): L'Orfeo favola, con música de Claudio Monteverdi, <www.librettidopera.it/zpdf/Orfeo.pdf> [fecha de consulta: 05/03/2013].

Tansillo, Luigi (1996): Il Canzoniere edito ed inedito secondo una copia dell'autografo ed altri manuscritti e stampe, ed. Erasmo Pércopo, vol. I: Poesie amorose, pastorali e pescatorie, personali, famigliari e religiose, Nápoles, 1926; reimpr.facsímil. Napoli, Liguori, pp. 95-96.

Tansillo, Luigi (2011): Rime, Tobia R. Toscano (ed.), con el comentario de Erika Milburn y Rossano Pestarino, 2 vols., Roma, Bulzoni.

Tasso, Bernardo (1995): Rime, Domenico Chiodo (ed.), Torino, Res.

Tasso, Torquato (1821): Rime... di nuovo corrette ed illustrati, I, Giovanni Rosini (ed.), Pisa <catalog.hathitrust.org> [fecha de consulta: 05/03/2013].

Tommaseo, Niccolò (1927): La Divina Commedia, con introducción de Umberto Cosmo, Torino, UTET, < dante.darmouth.edu> [fecha de consulta: 05/03/2013].

Varchi, Benedetto (2006): Rime, en Biblioteca italiana, <bibliotecaitaliana.it $>$ [fecha de consulta: 05/03/2013].

Vega, Garcilaso de la (2007): Obra poética y textos en prosa, Bienvenido Morros (ed.), Barcelona, Crítica.

Vega, Lope de (1969): Obras poéticas, José Manuel Blecua (ed.), Barcelona, Planeta. 
Vega, Lope de (1991): Obras escogidas. Poesía y prosa, vol.II: Poesías líricas, Federico Carlos Sainz de Robles (ed.), Madrid, Aguilar.

Vega, Lope de (1998): Rimas humanas y otros versos, Antonio Carreño (ed.), Barcelona, Crítica. Virgilio (1959): Énéide. Livres I-VI, Henri Goelzer y André Bellessort (eds.), Paris, Les Belles Lettres.

Virgilio (1988): Georgics. Books III-IV, Richard F. Thomas (ed.), Cambridge, University Press.

Fecha de recepción: 2 de marzo de 2013

Fecha de aceptación: 31 de julio de 2013 